\title{
Pembentukan posyandu remaja di Desa Bejiruyung, Kecamatan Sempor Kabupaten Kebumen
}

\author{
Wulan Rahmadhani1 ${ }^{*}$, Siti Mutoharoh ${ }^{2}$, Kusumastuti ${ }^{3}$, Adinda Putri Sari Dewi ${ }^{4}$ \\ 1,2,3,4 Sekolah Tinggi Ilmu Kesehatan Muhammadiyah Gombong
}

\section{INFORMASI ARTIKEL:}

\section{Riwayat Artikel:}

Tanggal diterima: 25 Juni 2021

Tanggal direvisi: 20 Juni 2021

Tanggal dipublikasi: 30 Juni 2021

\section{Kata kunci:}

Remaja

Posyandu

Pelatihan

Keyword:

Adolescence

Integrated Healthcare

Training

\section{ABSTRAK}

Latar Belakang: Masa remaja adalah masa peralihan antara anak-anak dan dewasa. Remaja masa kini mengahadapi tuntutan dan harapan, juga bahaya dan godaan yang lebih banyak dan kompleks. Apabila masalah itu tidak tertangani dengan baik bisa berdampak kepada masa depan serta berdampak pada kesehatan psikologisnya. Salah satu pencegahan bisa berupa keberadaan posyadu remaja yang dapat meningkatkan pengetahuan remaja. Permasalahan : Belum adanya posyandu remaja di Bejiruyung, Smpor kebumen. Solusi : Membentuk posyandu remaja. Tujuan : membentuk posyandu remaja dan kader remaja di desa Bejiruyung, Kecamatan Sempor Kabupaten Kebumen. Metode yang di lakukan pada pengabdian masyarakat ini adalah pelatihan kader posyandu yang di awali dengan persiapan yang di mulai dengan komitmen kepada remaja desa Bejiruyung, Kecamatan Sempor, Kabupaten Kebumen. Selanjutnya adalah pelaksanaan, antara lain penyuluhan dan pelatihan selama 2 kali yang meliputi materi dan praktek. Luaran : kegiatan pengabdian masyarakat ini adalah telah terbentuknya Fresh Beji (Forum Remaja Sehat Desa Bejiruyung).

Background: Adolescence is a transitional period between children and adults. Today's adolescent face demands and expectations, as well as more complex dangers and temptations. If the problem is not handled properly, it can have an impact in the future especially on the psychological health. One of the preventions can be in the form of the existence of a youth Integrated Healthcare (posyandu) that can increase adolescent knowledge. Problem: There is no youth Integrated Healthcare (posyandu) in Bejiruyung, Sempor, Kebumen. Solution: Establishing a youth Integrated Healthcare (posyandu). Objective: To form a youth Integrated Healthcare (posyandu) and youth cadres in Bejiruyung village, Sempor sub-district, Kebumen district. The method used in this community service was by training the Integrated Healthcare (posyandu) cadres which was began by committing the youth of Bejiruyung village, Sempor District, Kebumen Regency. Next was the implementation including counseling and training for 2 times included material and practice. Result: this community service activity has formed the New Beji (Bejiruyung Healthy Youth Forum).

\section{Pendahuluan}

a. Masa Remaja adalah masa peralihan antara anak-anak dan dewasa, berdasarkan WHO remaja di mulai dari usia 12 sampai denga 19 tahun dengan tugas perkembangan pencarian identitas diri (WHO, 2017). Pada fase remaja ini mereka bukan lagi disebut sebagai anak-anak dan bukan pula di panggil sebagai orang dewasa (Ani, 2015). Remaja pada saat ini menghadapi berbagai harapan dan tuntutan, godaan dan bahaya yang lebih kompleks di bandingkan dengan remaja generasi yang dahulu (Kemenkes $\mathrm{RI}$, 2018). Fenomena kebanyakan remaja di Indonesia sekarang ini mengalami kemunduran budi pekerti, moral serta kematangan emosi

\footnotetext{
* Korespondensi penulis.

Alamat E-mail: wulan@stikesmuhgombong.ac.id
} 
(Kementerian Kesehatan RI, 2017). Hal seperti ini dapat kita lihat dari kasus gaya hidup yang semakin ke barat-baratan serta pergaulan bebas yang semakin meningkat, kasus depresif seperti percobaan bunuh diri dan lainya (Kemenkes, 2018). Beberapa data mengenai perilaku maladaptive remaja menunjukan dari 2,4 juta perempuan melakukan aborsi dan 700-800 ribu itu termasuk dalam golongan remaja, dari 1283 kasus HIV/AIDS diperkirakan 52.000 terinfeksi dan $70 \%$ nya adalah remaja (Kementerian Kesehatan RI, 2017).

b. Dalam rangka memenuhi Permenes No 4 tahun 2019 tentang standar teknis pemenuhan mutu pelayanan dasar dalam bidang kesehatan yang salah satunya adalah pelayanan kesehatan pada usia Pendidikan dasar ditunjukan agar tiap anak memiliki kemampuan berperilaku hidup bersih dan sehat, tumbuh kembang secara optimal da menjadi sumber daya manusia yang berkualitas (Saraswati, 2018). kompleks nya permasalahan yang sudah terjadi di remaja tentunya memerelukan penanganan yang komprehensif dan terintegrasi yang melibatkan semua unsur dari semua lintas sektor terkait (Wahyuntari \& Ismarwati, 2020).

c. Permasalahan remaja yang ada di desa Bejiruyung adalah $35 \%$ remaja putri mengalami nyeri haid, 20\% remaja putri mengalami keputihan. Dari hasil wawancara di kemukakan bahwa remaja tersebut tidak mengetahui apa penyebab serta Tindakan yang mesti di lakukan untuk mengatasi masalah yang di alami mereka. Pada remaja putra terdapat $30 \%$ remaja yang berperilaku hidup tidak sehat yaitu merokok.

d. Salah satu yang menjadi upaya yang bisa mengurangi permasalahan yang terjadi pada remaja adalah dengan membentuk wadah untuk kegiatanb-kegiatan positif pada remaja yang biasanya di sebut dengan Posyandu remaja dimana kegiatan atau wadah tersebut diisi dengan berbagi pengetahuan dan informasiinformasi seputar kesehatan remaja khususnya kesehatan reproduksi (Sulastri, Astuti, \& Handyani, 2019).

e. Luaran dari kegiatan pengabdian masyarakat ini sendiri adalahterbentuknya kader posyandu remaja yang terlatih di desa Bejiruyung, Kecamatan Sempor, Kabupaten Kebumen

\section{Metode Pelaksanaan}

a. Kegiatan pengabdian masyarakat ini di laksanakan pada tanggal 05 Januari 2021 untuk proses persiapan yang meliputi analisis situasi, koordinasi dengan mitra, koordinasi dengan bidan desa dan tokoh masyarakat serta tokoh agama setempat. Kemudian pada tanggal 12 Januari 2021 dilakukan kegiatan tahap ke dua yaitu pembentukan posyandu remaja, yang pada sebelumnya sudah di bentuk struktur organisasi pada saat tanggal 10 Januari 2021 memalui musyawarah masyarakat desa. Setelah anggota menyetujui kegiatan selanjutnya adalah pembentukan kader remaja yang berusiakan 1418 tahun, yang berkomitmen, berjiwa kreatif dan inovatif serta mau dengan suka rela menjadi kader serta bertempat tinggal di desa Bejiruyung.

b. Tahap selanjutnya yaitu pelatihan kader posyandu remaja mengenai pelaksaan system 5 meja. Pelatihan di damping oleh bidan setempat dan juga di bantu oleh beberapa mahasiswa. Pelatihan ini di isi dengan beberapa materi terlebih dahulu antara lain, anemia pada remaja, kesehatan reproduksi. Kegiatan ini dilakukan 2 kali dan pada setiap kegiatan posyandu selalu di adakan penyuluhan terkait kesehatan remaja yang menjadi dasar atau landasan pengabdian masyarkat ini di lakukan.

c. Pada tahap terakhir adalah tahap evaluasi, dimna pada tahap ini dilakukan untuk mengetahui jalannya kegiatan posyandu remaja yang di bantu oleh bidan desa, kepala desa, tokoh agama dan tokoh masyarakat di desa Bejiruyung, Kecamatan Sempor, Kabupaten Kebumen.

\section{Hasil dan Pembahasan}

Pada kegiatan pengabdian masyarakat ini di bagi menjadi beberapa bagian atau tahapan, yaitu:

a. Tahap Persiapan

Didalam tahapan ini dilakukan sosialisati kepada kepala desa, bidan desa dan kepada karang taruna itu sendiri. Pelaksanaan di lakukan pada tanggal 05 Januari 2021 di kantor kelurahan desa Bejiruyung, Kecamatan Sempor, Kabupaten Kebumen. Pentingnya kegiatan sosialisasi ini adalah agar tujuan dari kegiatan posyandu remaja ini di laksanakn dengan berjalan lancar dan sesuai dengan memberikan pemahaman dan pengetahuan terhadap remaja. 
Telah terpilih 15 kader posyandu yang berasal dari anggota karang taruna desa Bejiruyung. Kader ini memiliki peran penting dalam terlaksananya kegiatan postyandu ini. Kader remaja ini yang nanti akan menjadi pelaksana dari kegiatan ini dimulai dari pencatan, skrining pemeriksaaan dan konseling terhadap remaja.

b. Tahap Pelaksanaan

Pada tahap ini bertempatan dibalai desa Bejiruyung yang di hadiri oleh kepala desa, bidan desa dan remaja setempat diluncurkan lah "Fresh Beji" (Forum Kesehatan Remaja Bejiruyung). Sebelumnya remaja yang terpilih menjadi kader sudah di bekali pengetahuan tentang posyandu dan simulasi kegiatan posyandu dari meja 1 sampai dengan meja 5 .

Kegiatan posyandu remaja di mulai dengan mempersiapkan daftar hadir peserta, buku konseling, buku kesehatan atau KMSR (Kartu Menuju Remaja Sehat), timbangan, tensu meter dan alat pengukur tinggi badan. Selain itu remaja juga menyiapkan kartu sehat remaja. Kegiatan posyandu ini di jadwalkan 1 bulan 1 kali pada minggu ke 4 dengan menggunakan system 5 meja antara lain:

1) Meja 1 merupakan trmpat pendaftaran peserta posyandu yang nanti akan mendapatkan antrian dan buku berisi data peserta.

2) Meja 2 merupakan tempat dimana peserta akan di lakukan pemeriksaan tekan darah, berat badan,tinggi badan dan pemeriksaan LILA.

3) Meja 3 mereupakan tempat pencatatan yang ada pada buku yang berisi data peserta tadi.

4) Meja 4 merupakan meja dimana para peserta posyandu di berikan penyuluhan. Kader membacakan hasil KMSR dan memberikan penyuluhan sesuai dengan kebutuhan atau keluhan dengan menggunakan alat bantu leaflet dan lembar balik.

5) Meja 5 pada meja ini biasanya di berikan pemberian tablet penambah darah (Fe) dan pemberian PMT bekerja sama dengan petugas keehatan dan bidan desa.

c. Tahap Evaluasi

Dalam tahap ini dilakukan monitoring/evaluasi kegiatan yang sudah di laksanakan. Kegiatan posyandu sakamandala dilaksanakan dengan kader sesuai yang sudah terbentuk di masing - masing meja, sehingga posyandu remaja Fresh Beji adalah kegiatan yang memang dilaksanakan oleh remaja dan untuk remaja. Pentingnya kegiatan evaluasi adalah untuk mengetahui apakah Posyandu berjalan sesuia dengan tujuan awal atau tidak, sehingga bisa diketahui tingkat keberhasilan suatu kegiatan.

Luaran dari kegiatan pengabdian masyarakat ini adalah terbentuknya Posyandu Remaja di Desa Bejiruyung kecamatan Sempor Kabupaten Kebumen dan telah terbentuk Posyandu Remaja dengan nama Posyandu Remaja Fresh Beji. Selain terbentuknya Posyandu Remaja bahwa telah terbentuk kader Posyandu Remaja dan telah dilakukan pelatihan kader Posyandu Remaja, sehingga kegiatan pengabdian masyarakat ini telah sesuai dengan tujuan awal yaitu terbentuknya Posyandu Remaja dan Kader Posyandu Remaja terlatih.

\section{Simpulan}

Hasil dari pengabdian masyarakat ini adalah telah terbentuk wadah bagi remaja yaitu "Fresh Beji" (Forum Kesehatan Remaja Beriruyung) di desa Bejiruyung kecamatan Sempor Kabupaten Kebumen dan tidak lupa terbentuk pula kader posyandu yang sudah terlatih

\section{Ucapan terima kasih}

Terima kasih kami ucapkan kepada Bejiruyung, Kecamatan Sempor Kabupaten Kebumen dan semua pihak yang telah membantu kelancaran kegiatan ini. 


\section{Daftar Pustaka}

Ani, L. S. 2015. Buku Saku Anemia Defisiensi Besi. In EGC.

Kemenkes. 2018. Remaja Indonesia Harus Sehat. Menkes.Go.ld.

Kemenkes RI. 2018. Remaja Indonesia Harus Sehat. Menkes.Go.Id.

Kementerian Kesehatan RI. 2017. Infodatin Reproduksi Remaja-Ed.Pdf. Situasi Kesehatan Reproduksi Remaja.

Saraswati, D. R. 2018. Pengelolaan Program Posyandu Remaja Di Pusat Management of Posyandu Adolescent Program in Information and. Jurnal Pendidikan Luar Sekolah.

Sulastri, E., Astuti, D. P., \& Handyani, E. W. 2019. Pembentukan Posyandu Remaja Desa
Madureso Kecamatan Kuwarasan

Kabupaten Kebumen. Urecol.

Wahyuntari, E., \& Ismarwati, I. 2020. Pembentukan kader kesehatan posyandu remaja Bokoharjo Prambanan. jurnal inovasi abdimas kebidanan (JIAK). https://doi.org/10.32536/jpma.v1i1.65

WHO. 2017. WHO | Adolescents and mental health. World Health Organization. 